\title{
LA JURISPRUDENCIA ROMANA CLÁSICA Y LA TEORÍA DEL VALOR
}

\author{
CÁNDIDA E. GUTIÉRREZ GARCÍA \\ Titular de Universidad de Derecho Romano
}

El presente trabajo pretende el análisis del pensamiento económico romano y en especial el de los grandes jurisconsultos, tema que nos interesa, como dice Connard ${ }^{1}$, no tanto por las concepciones doctrinales estrictamente económicas, cuanto por la repercusión que tuvieron los conceptos jurídicos de los grandes jurisconsultos en la teoría económica y en su realidad.

Si bien no encontramos en el Digesto una verdadera definición de los bienes en sentido económico, sí que los juristas romanos descubrieron cierta distinción entre las dos categorías de bienes, en sentido económico y en sentido no económico. Refiriéndose a ello, Marcelo, en el libro tercero de las Instituciones afirma: «Algunas cosas son comunes a todos por derecho natural, otras son de la comunidad, otras no son de nadie y la mayor parte son de particulares, las cuales se adquieren para cada cual por varias causas» ${ }^{2}$.

Ulpiano, en el libro 49 de sus Comentarios al Edicto, da una definición de bien que aún hoy podría se aceptada por la ciencia económica ${ }^{3}$ : «La palabra bienes tiene una significación o natural o civil; en la natural se llaman bienes porque bonifican, esto es, hacen feliz, bonificar es hacer provecho. Pero se ha de saber, que se computan en nuestros bienes no solamente las cosas que están en nuestro dominio, sino también lo que poseemos de buena fe o lo que usufructuamos; así mismo hay que computar entre los bienes, lo que está en las acciones, en las instancias y las acciones persecutorias; porque se considera que todo esto está en los bienes».

Aunque parece a primera vista que Ulpiano interpreta aquí un concepto de bien en sentido inmaterial, en relación con el hecho de que en la actual ciencia económica se discute si entre los bienes deben incluirse aún las cosas inmateriales, como por ejemplo las capacidades profesionales, sin embargo si examinamos a fondo el citado párrafo de Ulpiano, vemos que el concepto de bien al que se refiere es únicamente material.

Los juristas romanos no tuvieron un vocablo apropiado para definir lo que actualmente se conceptúan bienes o productos inmateriales, como la obra del

${ }^{1}$ Connard: Historie des doctrines economiques, I, París, 1924; p.39.

${ }^{2}$ D., $1,8,2$.

${ }^{3}$ D., $50,16,49$. 
médico, etc. Tydeman afirma que si bien los juristas no tuvieron el vocablo relativo al producto inmaterial, en sentido moderno, tuvieron empero el concepto de ello ${ }^{4}$. Sin emabrgo es más de aceptar la tesis de Tozzi ${ }^{5}$ que considera que los juristas romanos, aún en los ejemplos aducidos por Tydeman, entendieron siempre el producto como algo exteriorizado y expresado materialmente, aún cuando derivare casi exclusivamente de las capacidades intelectuales. Tales capacidades no son, en sí mismas, un producto, aunque constituyen el resultado de un trabajo educativo y didáctico; son en cambio causas o causas concomitantes del producto concreto y material. Sólo en un sentido indirecto aún los servicios --según los juristas romanos- son un bien.

Los romanos no desconocieron el concepto de valor subjetivo, si así expresa el grado de interés que un bien, o un conjunto de bienes, posee para los fines de bienestar de un sujeto económico. Alessio ${ }^{6}$ afirma que el primer origen de tal concepto es enteramente jurídico. Se reduce a la búsqueda de los elementos del resarcimiento del daño sufrido por el acreedor a cuasa del incumplimiento de la prestación, particularmente en las obligaciones de facere, donde el precio del mercado no puede servir de medida al interés, debido a que el objeto del contrato con frecuencia no posee valor general alguno, sino que lo tiene solamente para el acreedor. Así, por ejemplo, puede indagarse el valor de una caución para el stipulator en relación al cumplimiento de la obligación principal. Celso en su libro VI Digestorum afirma: «Si alguien estipuló de uno diez y de otro que se le diera caución, se habrá de estimar cuánto le importa al estipulante que se le dé la caución, y esto será $u$ otro tanto o menos, o a veces también nada, porque no hay estimación alguna de un vano temor, y pagado el capital no hay ya precio alguno para la estimación, o se deducirá de la estimación, tanto cuanto del capital se hubiese pagado.»

Existen todavía algunas consideraciones más estrictamente ligadas a los motivos económicos de la estimación. Así, a veces se busca qué valor tenga un bien para el que lo posee en relación a un determinado conjunto de bienes del que forma parte. Paulo afirma en el libro XXII al Edicto: «Asimismo se estiman las cualidades inherentes al cuerpo, si alguien hubiera matado a uno de los cómicos, o de los músicos o de los gemelos, porque no sólo se ha de estimar el cuerpo muerto sino que se ha de tener en cuenta en qué se depreciaron los demás cuerpos»?

A veces el valor subjetivo se une a una especial denominación, causa rei, que designa una relación de derecho o de hecho, en la que está un objeto respecto a otro, o un motivo que modifica el valor que el objeto tiene para el obligado.

\footnotetext{
${ }^{4}$ Tydeman: Disquisitio juridico-politica de economiae politicae notionibus in corpore juris civilis Iustinianei, Leyden, 1838; p. 79.

${ }^{5}$ Tozzi: Economistas griegos y romanos, México, 1974; p. 330.

${ }^{6}$ Alessio: Due saggi intorno ai concetti di valore nell'antiquitá clásica, Nápoles, 1981; p. 83.

${ }^{7} \mathrm{D} ., 9,2,22,1$.
} 
Pero la forma más completa y más concluyente del valor subjetivo viene dada por el precio de afección. Los romanos lo clasificaron con mucha agudeza, separándolo netamente del valor común, señalando cómo los precios deben referirse a un criterio de universal y constante utilidad en la que se reflejen, no las particulares estimaciones empíricas de un individuo aislado, sino los juicios de conjunto de los hombres. Por eso Paulo dice: «Si matase a mi esclavo, opino que no se ha de apreciar la afección, como si alguno hubiera matado a tu hijo natural, que tú quisieras estimarlo en mucho, sino en cuanto valiera para todos $»^{8}$. El mismo jurista, en el libro II de sus Comentarios a la ley Julia y Papia vuelve a repetir la misma idea: «Los precios de las cosas se establecen no por el afecto, ni por la utilidad de cada una de ellas, sino por la estimación común...»?

También del valor objetivo, entendido como el hecho por el que una cosa es apta para responder a un interés, a una necesidad o fin considerado en sí mismo, se encuentran muchos ejemplos en las doctrinas jurídicas de Roma. Los más frecuentes se refieren al valor residual, al valor patrimonial y al valor adquisitivo o de cambio.

Paulo, en el libro 32 al Edicto, nos ofrece un ejemplo del primero: «Si yo te hubiera dado en arrendamiento una casa ajena en cincuenta, y tú la hubieras dado arrendada a Ticio en sesenta y por el dueño se le hubiere prohibido a Ticio habitarla, parece bien que ejercitando tú la acción de conducción, debas conseguir los sesenta, porque tú mismo estás obligado a Ticio por los sesenta $\gg^{10}$.

Como vemos, aquí el conductor puede pedir lo que representa su obligación con respecto al inquilino: es evidente cómo la comparación está influida por el valor reditual que la cosa tiene para las partes que sacan provecho de él.

El valor testimonial se refiere ordinariamente a una cosa corporal, o en general a un asunto litigioso en su conjunto y asume la expresión usual de quanti res est, representando así las cualidades comunes y connaturales a la cosa, independientemente de las especiales ventajas que de ella se puedan percibir. Escribe Ulpiano en el libro 51 de sus Comentarios al Edicto: «Entre estas expresiones [cuanto valiere esta cosa] o [cuanto parece que vale esta cosa] no hay ninguna diferencia, porque está determinando que en una u otra cláusula se hace verdadera estimación de la cosa ${ }^{11}$.

Surge entonces la rei aestimatio y también, en forma más precisa, la vera rei aestimatio, con que alguna vez se intenta expresar un precio presente y no un precio aparente o formal. Así Paulo nos dice: «Si hay algunas cosas corporales en los bienes del difunto, habrán de ser estimadas conforme a la verdad de la cosa, esto es, según el precio presente, que no se ha de estimar cosa alguna de ellas según el precio formal» ${ }^{12}$.

$\mathrm{Al}$ valor patrimonial se refiere también el iustum pretium, pero en el sentido

\footnotetext{
${ }^{8}$ D., $9,2,33$, pr.

${ }^{9}$ D., $35,2,63$, pr.

${ }^{10}$ D., $19,2,7$.

${ }^{11}$ D., , 50, 16, 179 .

${ }^{12}$ D., 35, 2, 62.
} 
entendido por Paulo y Pomponio ${ }^{13}$ que lo conciben como resultado del debate recíproco entre los contrayentes, obrando con libertad y sin dolo malo. Toda excepción establecida más tarde a tal propósito, como el particular, el instituto de la laesio enormis ${ }^{14}$, las medidas relativas a las donaciones referidas a un cierto importe $\mathrm{y}$, en general, las decisiones administrativas de los precios, reflejan solamente el estado económico y social de las poblaciones en los últimos tiempos del Imperio Romano, y van solamente en tal sentido a restringir el alcance de un concepto propio de los períodos más florecientes del Derecho romano. Pero como dice Alessio ${ }^{15}$, la expansión más perfecta de un concepto económico aparece en el valor objetivo de cambio. Existen en el Derecho romano numerosos pasajes ${ }^{16}$ que confirman ésto y que distinguiendo los elementos del poder adquisitivo de la moneda, logran fundar en una relación natural y no artificial de cantidad, la base de cualquier valor de cambio.

Acertadamente señala Tozzi que no se puede negar a priori una referencia indirecta de los juristas a la cantidad de metal acuñado en general, por el hecho de que si esa cantidad debe expresar un valor, este valor, bajo el aspecto de la oferta, deberá estar en relación también con la cantidad en general de la moneda-mercancía y no únicamente con su cantidad específica utilizada en cada canje. Indudablemente la teoría cuantitativa de la moneda tiene mucha mayor afinidad con la de la monedamercancía que con la teoría de la moneda-signo. Casi podría decirse que el cuantitativismo es el lógico desarrollo del metalismo ${ }^{17}$.

Para confirmar la conformidad romana con la teoría de la moneda-mercancía, es significativo el siguiente pasaje de Gayo, que relaciona el poder adquisitivo con la cantidad del metal que sirve de moneda. «Por eso se utiliza el bronce - aes-y la balanza - libra - porque antes sólo se usaban monedas de bronce, y había ases, dupondios, medios ases, cuadrantes, y no se empleaban monedas de oro y plata, como puede verse en la Ley de las XII Tablas, y el valor y poder de esa moneda no residían en su cantidad, sino que consistían en su peso, puesto que había ases de una libra y dupondios de dos libras...»

Los romanos admitían que la moneda podría cambiar de valor respecto a los metales preciosos. Pomponio, en el libro VI de sus Comentarios al Edicto afirma: «El heredero a quien se le ordenó entregar cierto peso en plata a alguien (cui certum pondus argenti dare haeres iussus est) puede librarse de derecho, dando moneda constante, a condición de que en ese dinero esté el mismo valor (si in ea pecunia eadem estimatio fueri) ${ }^{18}$.

\footnotetext{
${ }^{13}$ D., $19,2,22,3$; D., 4, 4, 16, 4.

${ }^{14}$ D., $4,44,2$.

${ }^{15}$ Alessio, op. cit., p. 86.

${ }^{16} \mathrm{D} ., 18,1,1$.

${ }^{17}$ Tozzi: Economistas..., ed. cit; p. 376.

${ }^{18}$ D., $34,2,1,1$.
} 
De dos pasajes de los Códigos Teodosiano y Justinianeo dedujo Tydeman ${ }^{19}$ que los romanos conocían perfectamente la variabilidad del valor recíproco de los metales utilizados para las monedas y en un pasaje de Paulo ve la confirmación a su opinión: «...si alguien por razones de lucro (lucri causa) o de temor o de custodia, hubiere escondido alguna cosa bajo tierra, no existe tesoro $»^{20}$.

De las palabras lucri causa creemos se deduce que en este caso, las razones del ocultamiento del objeto precioso no pueden ser otras que la espera de un aumento del valor de canje del tal metal amonedado.

No obstante es preciso señalar que existe una gran confusión terminológica. Así, por ejemplo, en un texto de Hermogeniano, libro II de su Epítome del Derecho, se confunde entre el interés bancario y el interés común o singular. Evidentemente en este caso es muy fácil notar a qué interés se refieren, pero no deja de ser un problema que se utilice la misma palabra para significados tan diferentes: «Si el comprador hubiere incurrido en mora para pagar al vendedor le dará solamente los intereses, pero no todo lo que el vendedor pudo haber conseguido de no haber tenido lugar la mora, como por ejemplo si el vendedor fuese mercader y pudiera haber logrado con el precio de las mercancías un rendimiento mayor que los intereses $»^{21}$.

Lo mismo sucede en un pasaje del libro 23 de los Comentarios al Edicto de Ulpiano: «Entran en esta acción las siguientes cosas: en primer lugar el precio en que se vendió la cosa, igualmente los intereses del precio después del día de la entrega de la cosa, porque disfrutando ya el comprador de la cosa, es muy justo que pague él los intereses del precio 22 .

Pero a veces el cuadro más grave aún que el problema planteado es el que se da por confusión entre valor y precio que aparece en muchas ocasiones. En efecto, los juristas romanos se basan para la determinación del valor en factores objetivos por una parte y en factores polisubjetivos por otra. Ahora bien, el hecho de que consideren el valor como determinado por la utilidad social y el trabajo, y el precio como determinado por la utilidad subjetiva unida al hecho de que utilicen el término interés para señalar, por una parte, el interés de afección o utilidad subjetiva y, por otra, el interés común o utilidad social, así como su tendencia a igualar el precio con la utilidad subjetiva y a utilizar el término valor, lleva a confusión.

Así, por ejemplo podemos ver que en el libro 33 de Paulo en los Comentarios al Edicto, está igualando por una parte la utilidad subjetiva del comprador con el precio y, por otra, se iguala el valor al precio, porque se utiliza incorrectamente el término valor. En efecto, pues cuando dice en el texto ${ }^{23}:$ «Si el vino valiese más en el momento presente», debería decirse: «Si el vino tuviese mayor precio en el

${ }^{19}$ Tydeman: Disq..., ed. cit.; p. 376.

${ }^{20}$ D., $41,1,31,1$.

${ }^{21}$ D., $18,6,19$.

${ }^{22}$ D., $19,1,13,20$.

${ }^{23}$ D., $19,1,21,3$. 
momento presente» y que ésto es así podemos verlo en un texto de Ulpiano, en el libro 51 de sus Comentarios a Sabino: «Entre la frase [en lo que valiera la cosa] y [en lo que resulte valer la cosa] no hay diferencia, pues en ambas se admite que debe hacerse la estimación según el valor verdadero de la cosa $»^{24}$. Y en otro del mismo autor, en el libro 38 de sus Comentarios al Edicto, la frase [en lo que resulte valer la cosa] no se refiere al interés (del demandante) sino a la (verdadera) estimación de la $\cos a^{25}$ D., 50, 16, 193 donde podemos ver que se refiere a utilidad objetiva o polisubjetiva y no a la utilidad subjetiva, que es la que en muchas ocasiones igualan al precio.

También se utiliza incorrectamnte valor por precio en el libro 18 de los Comentarios a Sabino de Ulpiano: «En esta acción si se pregunta a qué momento debe referirse la estimación de la cosa que se pide, es lo más cierto lo que dice Servio, de que debe tenerse en cuenta el momento de la condena; y si (el esclavo) hubiera desaparecido, el de la muerte, pero como dice Celso, con amplitud, pues no debe referirse la estimación al último momento de la vida, no vaya a reducirse la estimación, cuando se trata de un esclavo mortalmente herido, a un precio exiguo» ${ }^{26}$.

El mismo error comete Ulpiano en el libro 28 de sus Comentarios al Edicto ${ }^{27}$ : «En esta acción a semejanza de las otras acciones de buena fe, se admite el juramento de litigio estimado, y se atiende el valor de la cosa en el momento del juicio, aunque en las acciones de (derecho) estricto, se atiende al momento de la litispendencia».

Y tenemos la más estricta separación de los tres conceptos en un pasaje del libro 28 de los Comentarios a Sabino, de Ulpiano, cuando dice: «Si la cosa vendida no se entregase, se demanda en la medida del interés del comprador por tener la cosa; lo que a veces excede del precio, si el interés del comprador es superior a lo que vale la cosa, o a la cantidad en que ha sido comprada $»^{28}$.

A veces el precio a largo plazo es igualado al valor en ciertos casos, y esto lo podemos constatar en otro texto de Paulo contenido en el libro 2 de sus Comentarios a la Ley Julia y Papia: «El precio de las cosas varía algo según los lugares y momentos: no se estimará el aceite en igual precio en Roma que en España; después de años estériles que de años de mucha producción, pero tampoco debe fijarse el valor por circunstancias transitorias ni por carestías excepcionales» ${ }^{29}$. En otras ocasiones se señala la existencia de un justo precio independiente del precio de compra o venta. Así, por ejempo, Ulpiano en el libro 44 de sus Comentarios al Edicto dice: «Preguntémonos cuál debe ser el criterio de un juez cuando (un liberto) haya vendido, arrendado o permutado algo en fraude de sus patronos. Cuando la cosa ha

\footnotetext{
${ }^{24} \mathrm{D} ., 50,16,179$.

${ }^{25}$ D., 50, 16, 193.

${ }^{26}$ D., 13, 3, 3 .

${ }^{27}$ D., 16, 6, 3, 2.

${ }^{28}$ D., $19,1,1$, pr.

${ }^{29}$ D., 35, 2, 63, 2.
} 
sido vendida, debe ofrecerse al comprador la elección entre pagar por lo comprado su justo precio o bien devolverlo a cambio de recuperar el precio (que pagó); porque no podemos resolver sin más la venta, como si el liberto hubiera carecido del derecho a vender, ni debemos defraudar al comprador en el precio, sobre todo cuando no se trata de su propio dolo, sino del dolo del liberto» ${ }^{30}$.

Podemos ver, por una parte, que la justa estimación no es otra cosa que el justo precio, y por otra que ese justo precio no tiene nada que ver con el precio - al menos necesariamente-.

Pero en cualquier caso, donde mejor puede verse que valor y precio no son la misma cosa es en el libro 34 de los Comentarios al Edicto de Paulo: «Del mismo modo que al comprar y vender se admite como natural el comprar en menos lo que vale más, o vender en más lo que vale menos, y aprovecharse así de la otra parte, lo mismo vale también en el arrendamiento» ${ }^{31}$.

De todo lo expuesto se sigue que, en efecto, se diferencia entre valor y precio, siendo el valor el precio justo, el precio a largo plazo, el plazo de utilidad social, y el precio la cuantía de dinero pagada realmente, la utilidad subjetiva.

A este respecto merece la pena notar lo dicho por Paulo en el libro 2 de las Cuestiones: «Respecto a los gastos que el comprador hizo al instruir al esclavo, habrá que ver, pues estimo que la acción de comprar es suficiente en este supuesto, porque no comprende solamente el precio, sino todo el interés del comprador en que el esclavo no fuera objeto de evicción. Claro que dice que el precio excedió tanto que el vendedor no pudo pensar en suma tan grande (por ejemplo, si supone que el que se había vendido se hizo conductor de coches de carreras o actor de teatro y luego fue objeto de evicción), parece injusto obligar al vendedor en una gran cantidad». Donde aparte de poder ver una vez más el intento de buscar un precio justo, podemos comprobar el interés de que se pague, aunque a nosotros nos choque actualmente, el costo de producción. Y hay que tener en cuenta que el pago del valor, donde parece injusto es precisamente en ese tipo de artículos que los economistas clásicos denominarán posteriormente «de lujo» y como consecuencia, fuera del funcionamiento normal del valor.

Por otra parte, se piensa también en el trabajo como base del valor. Así por ejemplo, Paulo en el libro 7 de los Comentarios al Edicto: «Labeón y Sabino opinan que, si se devuelve un vestido rasgado o estropeado, se entiende que falta, lo mismo que unas copas quebradas o una tabla con la pintura rasgada, pues su valor no está en la madera, sino en el arte ${ }^{32}$, donde claramente arte significa trabajo. Así pues, podemos ver que los juristas romanos hablan del valor y del precio citando tanto la utilidad como el costo. Y si bien para el precio se trata únicamente de la utilidad individual, para el valor se trata de la utilidad social y del trabajo.

\footnotetext{
${ }^{30} \mathrm{D}, 38,5,1,12$.

${ }^{31}$ D., $19,2,22,3$.

${ }^{32}$ D., $50,16,14$.
} 
Como conclusiones más importantes a que nos lleva el presente trabajo de investigación son las siguientes:

1‥ La teoría del valor es uno de los puntos más controvertidos a lo largo de la historia del pensamiento económico.

2 a . En el Digesto no se nos da una verdadera definición de los bienes en sentido económico, por el contario, los juristas romanos distinguieron las dos categorías de bienes, en sentido económico y en sentido jurídico.

3 a . El concepto de valor ha sido tratado por la jurisprudencia clásica, tanto desde un punto de vista subjetivo (goce, placer, escasez) como desde un punto de vista objetivo (trabajo, coste, etc.).

$4^{\mathrm{a}}$. El concepto subjetivo del valor —en los juristas romanos - tiene su origen en un concepto jurídico, como es la búsqueda de los elementos del resarcimiento para el acreedor por el daño sufrido ante el incumplimiento de la prestación de hacer.

5 . También el valor objetivo entendido como el hecho por el que una cosa es apta para responder a un interés, necesidad o fin considerado en sí mismo, fue tratado por los juristas romanos. Los ejemplos más frecuentes son los referidos al valor reditual, al valor patrimonial y al valor de cambio.

$6^{\mathrm{a}}$. Al distinguir los elementos adquisitivos de la moneda logran fundar en una relación natural y no artificial de cantidad cualquier valor de cambio.

$7^{\text {a }}$. Los jurisconsultos romanos en numerosos textos diferenciarán los conceptos de valor y precio, aunque existe en ellos confusión terminológica. 